\title{
A SOCIO-TECHNICAL INTERVENTION IN BIM PROJECTS - AN EXPERIMENTAL STUDY IN GLOBAL VIRTUAL TEAMS
}

SUBMITTED: February 2021

REVISED: May 2021

PUBLISHED: July 2021

GUEST EDITORS: Kirti Ruikar, Ketan Kotecha, Sayali Sandbhor, Albert Thomas

DOI: $10.36680 /$ j.itcon.2021.026

Anne Anderson, Ph.D., Associate Professor

School of Engineering,

Computing and Construction Management, Roger Williams University, Bristol, Rhode Island, USA

email: akanderson@rwu.edu

\author{
Shobha Ramalingam, Ph.D., Associate Professor \\ School of Construction Management, \\ National Institute of Construction Management and Research (NICMAR), Pune, Maharashtra, India \\ email: sramalingam@ms.nicmar.ac.in
}

\begin{abstract}
SUMMARY: 'Global Projects' and 'Global Virtual Teams' are revolutionizing the construction industry. An increasing number of multi-national engineering firms are adopting this business model due to the possible advantages of cost and time optimization. However, literature identifies several challenges that the project teams endure in temporarily organizing while transitioning through time and space, some of which include cross-cultural differences in teams and limited richness of the communication media. Perceiving virtual project execution as a multi-variable construct, organizational theorists and sociologists adopt a socio-technical approach to understand the dynamics of action embedded in the process and recommend implementation of pre-process, during process or post process intervention strategies to enable performance. In this paper, we address this research concern through an experimental study conducted across two global universities, National Institute of Construction Management and Research, Pune, India and Washington State University, USA. Around 24 students from each university in ten teams collaborated virtually for a period of 2.5 weeks to develop a 3-dimensional Revit model and a 4-dimensional BIM model in Autodesk Revit and Navisworks, respectively, for a multi-storey residential building. The study aimed to investigate the role of project teams in organizing and coordinating projects tasks and taking a socio-technical approach, explored the role of a BIM Execution Plan as a pre-process intervention strategy. Data collected through qualitative survey post the experiment was qualitatively analyzed using ethnographic coding techniques. Findings showed that the project and team challenges primarily stemmed from coordination issues and institutional differences. Members significantly mitigated the issues through a proactive approach and a priori planning. The BIM Execution Plan allowed members to instantly get involved with the tasks and plan the process apart from being able to foresee the complexity. Teams emphasized the importance of implementing a detailed BIM Execution Plan during the planning phase for a collaborative and successful project outcome and further observed that pre-process intervention strategy such as a BIM plan was the needed impetus for members to collaborate and coordinate project tasks.
\end{abstract}

KEYWORDS: Global Virtual Teams, Socio-technical Approach, Pre-process Intervention, BIM Execution Plan, Process Performance.

REFERENCE: Anne Anderson, Shobha Ramalingam (2021). A socio-technical intervention in BIM projects - an experimental study in global virtual teams. Journal of Information Technology in Construction (ITcon), Special issue: 'Next Generation ICT - How distant is ubiquitous computing?', Vol. 26, pg. 489-504, DOI: 10.36680/j.itcon.2021.026

COPYRIGHT: () 2021 The author(s). This is an open access article distributed under the terms of the Creative Commons Attribution 4.0 International (https://creativecommons.org/licenses/by/4.0/), which permits unrestricted use, distribution, and reproduction in any medium, provided the original work is properly cited. 


\section{INTRODUCTION}

Globalization and advancement in technology is profoundly changing the business practices in Multinational Corporations. Government policies world-wide are favouring the participation and presence of multi-national entities in execution of mega projects within a country. In a survey, Pricewaterhouse Coopers informed about the cross-border integration and the unprecedented growth in global business (Pwc, 2012). Researchers have thus far coined cross-border cooperation as 'institutionalized collaboration' (Perkmann, 2003), 'transnational projects', and 'global projects' (Anantatmula and Thomas, 2010). Orr et al. (2011) defines a 'global project' as a temporary endeavor, where, multiple actors seek to optimize outcomes by combining resources from multiple sites, organizations, cultures, and geographies through a combination of contractual, hierarchical, and network-based modes of organization. Further, researchers including Hertel et al. (2005) have observed that one of the contemporary solutions to cross-border collaboration is by engaging virtual teams in various phases of the project execution.

Building Information Modeling (BIM) is a collaborative tool enabling the various stakeholders of a project in the Architecture, Engineering and Construction (AEC) industry to insert, extract, update and modify information at different phases of the project life-cycle of a facility (Eastman et al., 2011). Taking advantage of this collaborative feasibility, several multinational engineering firms are practicing global sourcing strategies such as 'outsourcing', 'offshoring' or 'offshore outsourcing' wherein work is packaged either to their own subsidiary located in a different country (offshoring) or to a different firm which specializes in the task in another country (offshore outsourcing). In general, non-core or repetitive tasks such as development of shop drawings from structural designs or developing 3-dimensional (3D) or 4D BIM models from 2D drawings are packaged. However, recently, certain firms are also practicing to package core activities such as design development process of a project (Leonardi and Bailey, 2008).

Some of the benefits of adopting such a business strategy include: tapping global expertise or talent pool, roundthe clock execution of work (due to differences in time zones) and economizing on project costs (Messner et al., 2007). While these sourcing strategies are feasible and lucrative, researchers have noted the embedded challenges in such project execution which primarily stem from the inherent features of global projects or virtual team phenomenon due to project complexity and uniqueness, cross-cultural teams that are multi-disciplinary and globally distributed, and technology-mediated interaction with limited or no face-to-face interaction (Scott et al., 2011; Iorio et al., 2011). As industry moves towards distributed work, it is imperative to shift the focus from project and task level to team level in order to understand the dynamics of globally distributed teams and their impact on project performance. In this paper, we review some of the distinct literature from global virtual team studies that highlight the challenges impeding successful project delivery, followed by a description of the global project research setting, and data collection and analysis methods. By examining documents such as team reports and qualitative survey results using a socio-technical systems approach, we aim to have a more thorough understanding of how pre-process interventions impact collaboration across geographical, institutional, and disciplinary boundaries.

\section{LITERATURE REVIEW}

Virtual teams are temporary in nature and assemble on as-needed basis, for specific project deliverables across organizations. Virtual teams primarily rely on electronic communication to organize and work together, both synchronously and asynchronously to accomplish their tasks (Jarvenpaa and Ives, 1994). Virtual teams have been deployed in sectors such as aerospace (Malhotra et al., 2007), healthcare (Cooley, 2020), manufacturing (May and Carter, 2001), and product development (Akkirman and Harris, 2005; Maznevski and Chudoba, 2000), enabling individuals to avoid counterproductive travel and contribute to multiple teams simultaneously, while providing the organization access to diverse talent (Malhotra et al., 2001). Continuous improvements in information and communication technologies (ICTs), combined with a shift from production-based to knowledgebased work, have allowed virtual teams to flourish (Becerik-Gerber et al., 2012; Kayworth and Leidner, 2002) and the COVID-19 pandemic necessitated their use for many organizations that may not have otherwise considered it (Cooley, 2020; Newman and Ford, 2021; Whillans, et al. 2021).

Researchers contend that such technology-mediated interaction with the degree of virtualness in the 
communication media, augmented by limited or no prior acquaintance with team members and the need to span several boundaries including geographical, temporal, organizational and cultural, can be quite challenging (Levina and Vaast, 2005; Espinosa et al., 2003). For instance, virtualness limit the possibility of team members to develop a shared understanding to collaborate and accomplish project tasks. Further, due to asynchronous communication and in the absence of informal cues, information could be misinterpreted leading to costly project delays (Daft and Lengel, 1986). Further, a key concern is that electronically mediated communication may hinder understanding and complicate knowledge transfer, especially with information that is complex and ambiguous (Gibson and Gibbs, 2006). Similarly, studies by Iorio et al. (2011) highlight competing factors that impact the usage patterns of collaborative tools and its ability to promote group cohesion. All these insights highlight that virtual project executions are prone to collaboration and coordination challenges.

Looking beyond in the BIM era, BIM tools pose both as a challenge and as an opportunity in the AEC industry (Elmualim and Gilder, 2014). However, literature on BIM as a collaborative tool is not clearly articulated. Researchers contend that even with the plethora of research and investment in the deployment of BIM, its use is not in the mainstream practice (Sackey et al., 2015) but rather is deployed primarily on large projects (Oakley, 2012). Few studies such as Kim et al. (2017) acknowledge the value of implementing BIM to reduce project delays. On the other hand, discussing the effects of BIM, Liu et al. (2017) identify key constructs such as technology management, attitude and behavior, role taking, trust, communication and leadership in a design and construction project. Similarly, Merschbrock and Munkvold (2015) discuss change agents, BIM contracts and the need for new roles and responsibilities that are different from traditional ones. As informed by Eastman et al. (2011) organizations have to therefore change their processes to adapt to this new development. In retrospect, Poirier et al. (2017) connote that 'the impact of BIM on collaboration is understood as a reshaping of an individual's cognitive determinants, which influence a team member's framing of event patterns enacted throughout project delivery'. This involves a systems thinking approach.

Further, researchers have extensively explored BIM implementation and integration challenges. Criminale and Langar (2017) identified 36 barriers to BIM implementation and contend that extensive training time needed for employees, lack of national standards for BIM, interoperability issues of the software, huge investment costs were some of the significant factors. To enable teams in integrating BIM into construction projects, several international organizations have developed BIM Execution Plan (BEP) frameworks such as the U.S National BIM standard, the U.K. BSi Standard Framework, the Guide to BS1192 and the Pennsylvania State University BEP proposed by the Computer Integrated Construction Research Program (CICRP, 2010). BEP is a structured collaborative planning guide that specifies roles and responsibilities of team members and directs BIM usage in the modeling process. It contains details with regard to deliverables and the process through which the deliverables are created, maintained and shared in order to meet specific project goals by different stakeholders. Most of such frameworks focus on the pre-operation or during operation phase. Interestingly, Lin et al. (2016) proposed a BIM Plan for post operation activities such as facility management. Nevertheless, Kunz and Fischer (2020) connote that Virtual Design and Construction (VDC) framework integrates an organization perspective with processes that are implicit in Virtual Design Teams including 3D BIM process. VDC methods are now adopted by several business units to improve project performance.

This insight triggers interest to explore BIM practices and process through a systems perspective as also observed by researchers who have utilized various conceptual frameworks to guide in the implementation of complex IT systems in organizations. For instance, Sackey et al. (2015) observe that traditionally, IT implementation assumes a stable work process with routine tasks. However, due to the complex, reciprocally interdependent and heterogeneous nature of construction projects, such an assumption would fail. Taking a socio-technical systems perspective, Sackey et al. (2015) therefore demonstrate that 'the normally held logics of linear adaptation of tools to institutional patterns do not hold true in the construction context,' and therefore BIM users must be positioned to constantly learn from the 'ever-evolving BIM artifacts and the concomitant work practices'. In this tradition, Whyte (2013) also points out that the idea of BIM in the AEC sector must explore the changing nature of BIMenabled project-based work to understand how the roles, both through cooperation and through managerial approaches, co-exist in different knowledge works.

As a point of departure, it therefore seems natural to explore virtual team performance through a socio-technical systems perspective following Hendrick (1997) for a comprehensive and integrated understanding of the multivariable constructs that impact the virtual team process. The socio-technical system comprises the technological 
sub-system (e.g., media richness) that interacts with the personal sub-system (e.g., group composition) and task characteristics (e.g., task complexity) to influence the team's attitudes and behaviors, and subsequent task performance (Bos et al., 2002; Carey and Kacmar, 1997). Flore et al. (2003) put forth a framework within the context of a socio-technological coordination space, wherein the primary components are composed of the attitudes, behaviours and cognition of virtual teams that may emerge at various phases of interaction among team members. Such interactions may occur, prior to the process, during the process and after the process. For instance, a pre-process interaction would involve activities such as project planning, clarifying group and task goals and setting standards which may lead to commitment and enhanced task and team performance. Similarly, in-process interactions occur during actual task execution and they could focus on developing the team skills such as on communication and coordination through training to create an environment of shared understanding (CannonBowers et al., 1995). Post process interactions would include post-task reflection on performance such as after action review or the feedback loops that in turn influence the personal subsystems action. For instance, de-briefing sessions could foster positive team efficacy (Cannon-Bowers et al., 1993) and such antecedent or consequent behavior could be critical to team development and successful execution of the team processes. Some of the earlier experimental studies have also demonstrated how facilitators (Comu et al., 2013), boundary spanners (Ramalingam and Mahalingam, 2011; DiMarco et al., 2010), and technology leaders (Iorio \& Taylor, 2015), as interventions, impact virtual team performance.

In sum, these insights draw our attention to process interventions that can be interposed to facilitate learning, bridge the knowledge gaps, overcome cross-cultural conflicts and steer performance. Thus, taking a sociotechnical perspective, the question explored here is, 'can the BEP act as a pre-process intervention to enhance team performance?' To this end, this study addresses two research questions:

- How do global virtual teams organize to execute global design and construction projects?

- How does BIM Execution Plan act as a pre-process intervention strategy and influence project and team performance?

\section{RESEARCH METHODOLOGY}

\subsection{Research Setting}

The global virtual team experiment has been conducted yearly since 2008 with specific research objectives across global universities. It was originally developed by researchers at Columbia University, USA, in collaboration with Indian Institute of Technology Madras, India, University of Twente, Netherlands, and Aalto University, Finland. Some of the research objectives involved exploring the impact of collaborative tools (Iorio et al., 2011), how facilitators impact formation of team knowledge structures (Comu et al., 2013) and the role of boundary spanners (DiMarco et al., 2010; Ramalingam and Mahalingam, 2011) in virtual team performance. Several other universities participated in the subsequent years including National Taiwan University, Taiwan; National Cheng Kung University, Taiwan; Yonsei University, South Korea; National Institute of Construction Management and Research (NICMAR), Pune, India; University of Washington, USA, and Washington State University (WSU), USA. The areas further explored included the impact of collaboration using BIM (Dossick and Neff, 2011) and achieving knowledge synthesis through messy talk (Dossick et al., 2014). Apart from the research orientation, these experiments were found to be of immense educational value. For instance, they provided the needed impetus for the students to develop their techno-managerial skills in order to be able to adapt to the growing 'flat world' and span their capabilities across geographical, temporal and cultural boundaries (Dossick et al., 2015).

This study is based on the experiment conducted in 2019, wherein Master level graduate students from NICMAR, Pune, India and undergraduate students from WSU, USA collaborated together to develop a BIM model for a period of 2.5 weeks from 18th March to 5th April, 2019. The overall project was for 5 weeks. This experiment was therefore conducted in two phases, wherein phase-I (the first 2.5 weeks) was collaborative across universities and phase-II (the next 2.5 weeks) was in-house, within each university, to accommodate the changes in the academic modules. A total of 25 NICMAR and 45 WSU students \{comprising 22 Construction Managers (CM) and 23 Designers $\}$ in ten teams participated in this multi-disciplinary global team experiment. Each team therefore comprised of 6 to 9 members with 2-3 NICMAR students, 2-3 WSU CM students and 2-3 WSU Designers. 


\subsection{Project Details}

The Project required the teams to collaboratively build BIM models of a multi-storey residential apartment as a disaster response to recent floods in Chennai, India. The project tasks therefore included developing a BIM Execution Plan and preparing the project schedule in Primavera software, generating a 3D model in Autodesk Revit software, building a 4D model in Navisworks and creating a cost estimate in Autodesk Assemble, all for the same project. Table 1 shows the project timeline and weekly deliverables.

Table 1: Project Schedule

\begin{tabular}{|c|c|c|c|}
\hline Week & $\begin{array}{l}\text { Week of: } \\
(2019)\end{array}$ & $\begin{array}{l}\text { Task and Responsibilities (WSU - CM, WSU } \\
\text { Designers \& NICMAR members) }\end{array}$ & (due at both \\
\hline 1 & March 18 & $\begin{array}{l}\text { BIM Execution Planning (WSU CMs lead, } \\
\text { NICMAR and WSU designers contribute); 3D } \\
\text { Modeling (NICMAR) }\end{array}$ & $\begin{array}{l}\text { BIM Execution Plan - WSU CM; 3D } \\
\text { Model - NICMAR }\end{array}$ \\
\hline 2 & March 25 & $\begin{array}{l}\text { Constructability Review (NICMAR and WSU } \\
\text { Designers) }\end{array}$ & $\begin{array}{l}\text { Construction Schedule - WSU CM; } \\
\text { Constructability Report - NICMAR, } \\
\text { WSU Designers }\end{array}$ \\
\hline 3 & April 1 & $\begin{array}{l}\text { Construction Simulation (WSU CM); Revise } \\
\text { the 3D Model based on Week } 2 \text { Review (WSU } \\
\text { Designers) }\end{array}$ & $\begin{array}{l}\text { Construction Simulation - WSU CM } \\
-\quad 4 D ; \text { Optimized 3D Model - } \\
\text { NICMAR, WSU Designers }\end{array}$ \\
\hline 4 & April 8 & Cost Estimate (WSU CM) & Cost Estimate \\
\hline 5 & April 15 & Summary Report (All) & Summary Report \\
\hline
\end{tabular}

Prior to the start of the collaborative experiment, the student teams in each university had also experimented handson to develop a 3D BIM model for addition of two rooms to an existing structure. This ensured that the students had a base knowledge to develop 3D BIM models prior to collaboration. However, BIM Execution Plan (BEP) was introduced only for the collaborative experiment, as a pre-process intervention strategy in the project.

In week 1, the project work therefore started with the WSU CM members leading the team to create the BIM execution plan and filling out necessary information for review by others on the team. This included structuring the project with all necessary protocols including communication and file sharing methods for the team apart from identifying roles and responsibilities, setting milestones and deadlines. The BEP framework put forth by Pennsylvania State University served as a template (Anumba, 2010). In parallel, NICMAR members of the team collaborated with WSU Designers to develop the Revit 3D model as shown in Table 1.

In week 2, while the WSU CM members generated the project schedule, the WSU designers and NICMAR members collaborated to optimize the built 3D model. Some of the project criteria was to build quickly as a response to disaster management (preferably in months) and find ways to reduce cost, all of which involved brainstorming to review the constructability issues and understand the Indian construction practice by all members of the team.

In week 3, while WSU CM members of each team developed the 4D simulation in Navisworks, an optimized 3D model was developed together by NICMAR and WSU Designers. Fig. 1 shows some of the models and revisions resulting from the constructability review.

Beyond this, there were school specific modules in which WSU team members (CM and Designers) were required to create the cost estimate in Assemble in week 4 and submit a summary report in week 5. NICMAR members were constrained by their term end examinations to collaborate further. However, the collaboration ended with the submission of a common report to both the universities explaining strategies adopted by the teams to reduce cost and duration of the project as well as team processes and communication methods adopted. The entire experiment was designed to make the collaboration iterative and interdependent. 

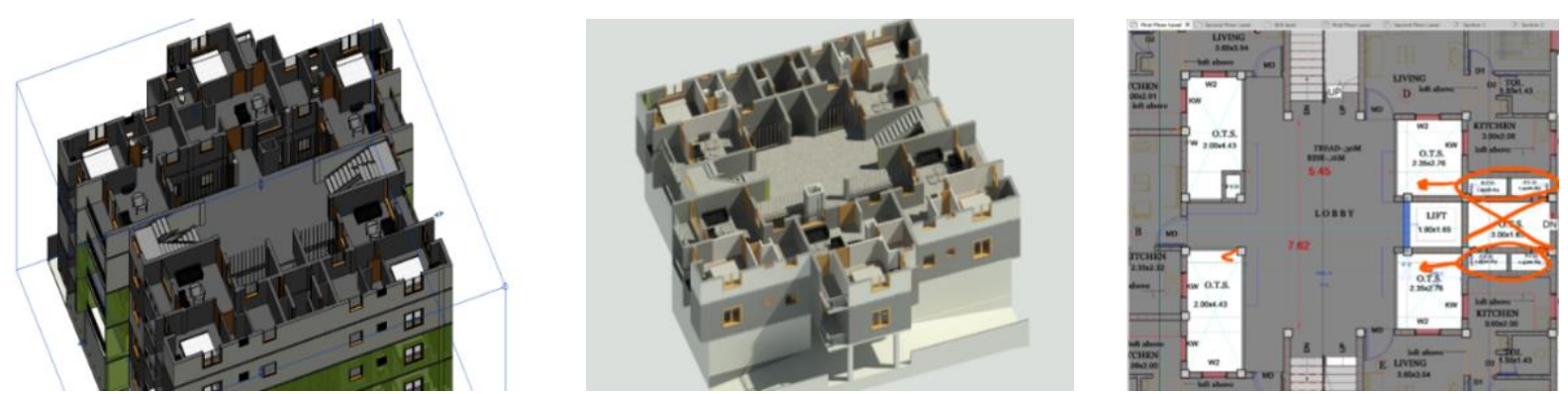

FIG.1: (Left) 3D Revit model; (Middle) 3D Revit model; (Right) Floor plan showing post-constructability review revisions

\subsection{Data Collection and Analysis Methodology}

The experiment was a synthetic laboratory experiment wherein student teams developed BIM models in a virtual setting and coordinated tasks across cultural and temporal boundaries. Adopting a socio-technical perspective, the dynamics of team interactions such as the challenges and resolution methods adopted, the pre-process intervention strategy and their outcomes on project and team performance and, also, the reflections or learning outcome of the team members were of interest to explore. Researchers have often emphasized capturing rich data through qualitative methods where experiments have involved human expertise or to understand the 'how' of the dynamics of team interactions (Bernould and Lee, 2010, Phelps and Horman, 2010). Along these lines, Creswell (1998) suggests five types of qualitative research methods that represent long-lasting traditions in social science which include: biography, phenomenology, grounded theory, ethnography and case study. Direct 'interviews' and participant 'observation' are notable means to collect rich data for qualitative studies. For instance, Leonardi and Bailey (2008) explore the role of collaborative technologies using grounded theory technique through observation and interviews to describe five emergent work practices in outsourcing firms. Deriving from Creswell (1998), Jansen (2010) argues that data for qualitative studies could also be captured through a 'qualitative survey' tool with semi-structured and open-ended questions to qualitatively investigate the variation in population, where immersive data collection was not feasible. The qualitative type of survey does not aim at establishing frequencies, means or other parameters but it helps to determine the diversity of member characteristic or a specific topic of interest within a given population (Jansen, 2010). Thus, due to the distributed team locations and academic schedules, a qualitative survey technique was adopted to collect data.

The survey instrument comprised of a series of semi-structured but open-ended questions, probing the dynamics of team performance, which was floated post the experiment, to all the team members across the two universities, to capture their reflections on the global team experiment. The questions focused on three aspects: a) individual and team level reflections on both the project and team level performance and their challenges, b) BIM execution plan and modeling related experiences and c) overall experience and recommendations. Some of the questions included: 'What were your individual and team level lessons learned in this exercise?', 'What were the project and team related challenges and how were they addressed?', 'What were the collaborative and non-collaborative assumptions made in the project?', 'How were the coordination issues resolved?', 'What were the benefits and limitations of incorporating BIM Plan in the modeling process?', 'What were the challenges in implementing BIM Plan in 3D and 4D models?', 'What were the things you liked or did not like about the global team experiment?', 'What are your recommendations for firms executing projects through distributed and multi-cultural teams?'. To enable triangulation and reveal contradictions in reporting of events, other data sources collected included the team reports and presentations submitted to each university. The response rate of the survey instrument was $81 \%$ wherein, 57 out of the 70 students from both the universities responded.

Data were subsequently analyzed qualitatively and ethnographically coded to identify constructs and emergent themes. To ensure accurate coding, the constant comparison method and inductive reasoning was used as informed by Strauss and Corbin (1998). Further, as there is no single step to rigorously conduct qualitative data, a thematic content analysis was also performed that helped to develop a plausible account of 'why the observed outcomes were what they were' (Anderson, 1998). 


\section{RESULTS AND FINDINGS}

This section presents the analysis of the survey results triangulated with other data sources. The findings are presented in the following three sub-sections that describe: a) individual and team level reflections on project and team related performance and challenges, b) modeling and BIM execution plan related learnings and c) overall experience and recommendations. However, foremost participant background information is presented below as evident in Fig. 2:

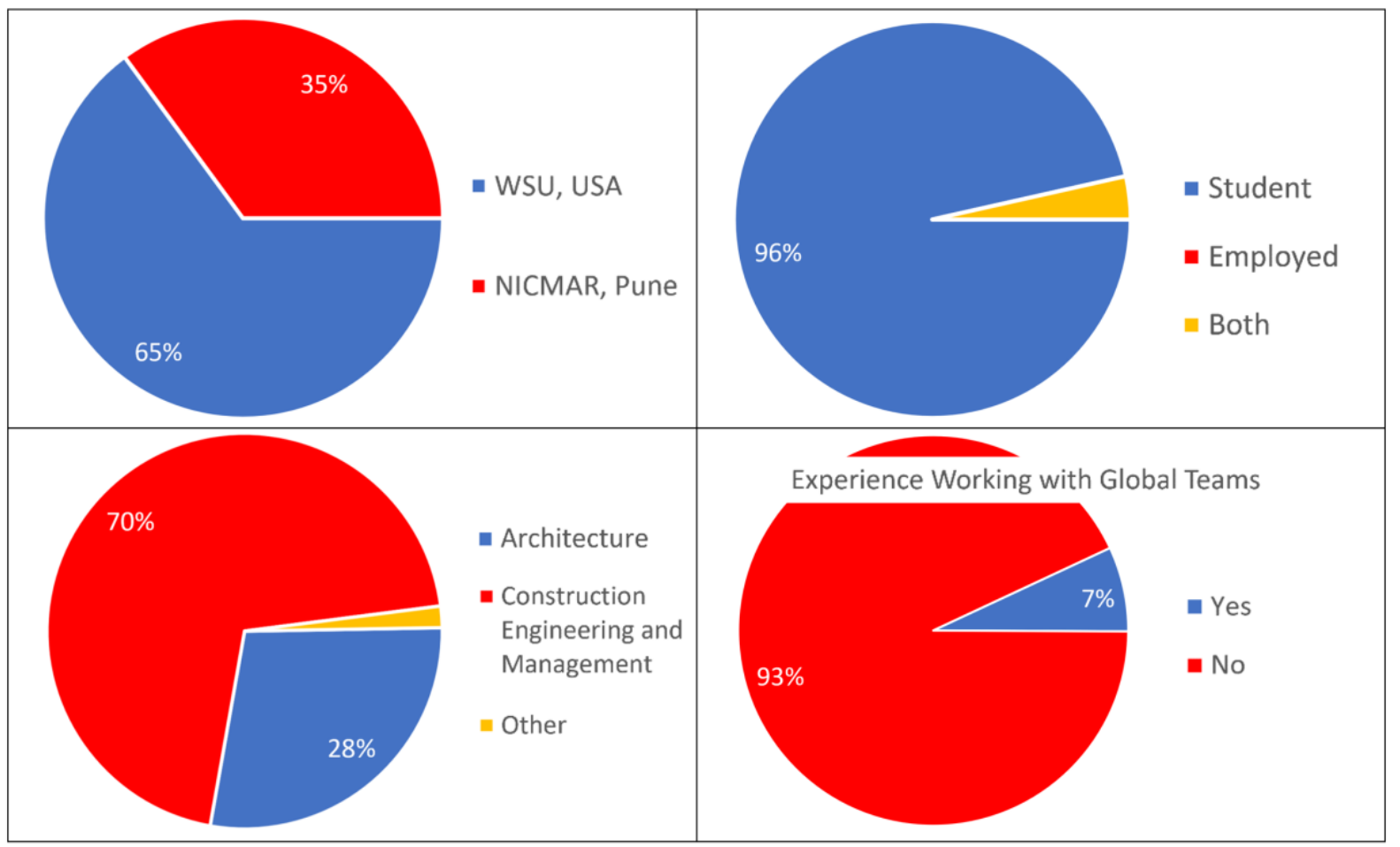

FIG. 2: Participant Background

The survey results showed that $91 \%$ of the respondents were students in the age group of 20-25 years. Around 4\% of them were also employed. $70 \%$ of them were specializing in Construction Engineering and Management discipline while $28 \%$ of them were Architects. $93 \%$ of the respondents reported that they did not have any earlier experience working in virtual teams. The members of NICMAR were all Indians while the WSU members were a mix of nationalities - a cross-cultural team (Fig. 3). Around $20 \%$ of the respondents had over six months of experience using BIM while nearly $40 \%$ had no experience as evident from Fig. 4.

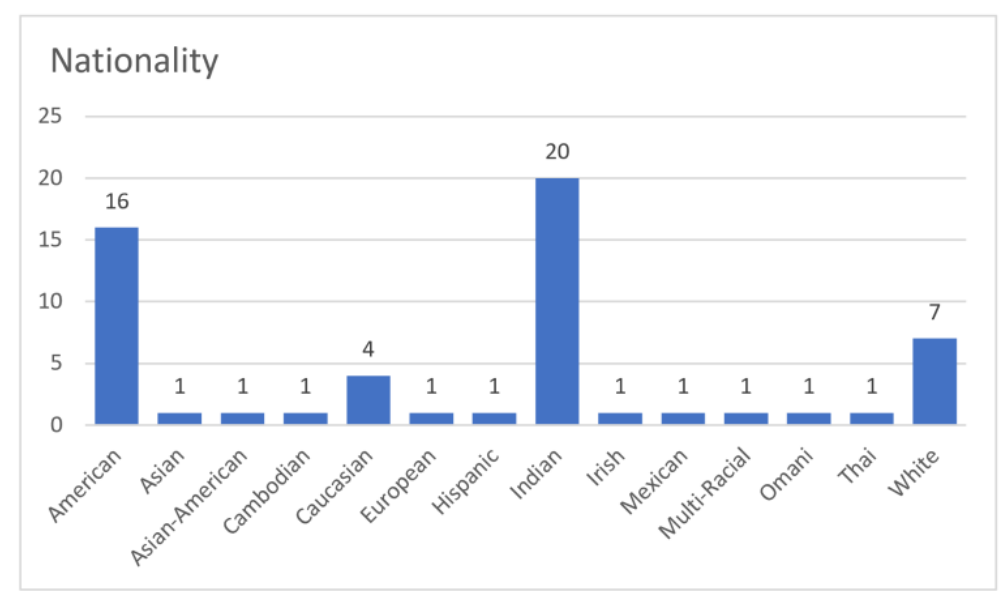

FIG. 3: Participant Team Composition 


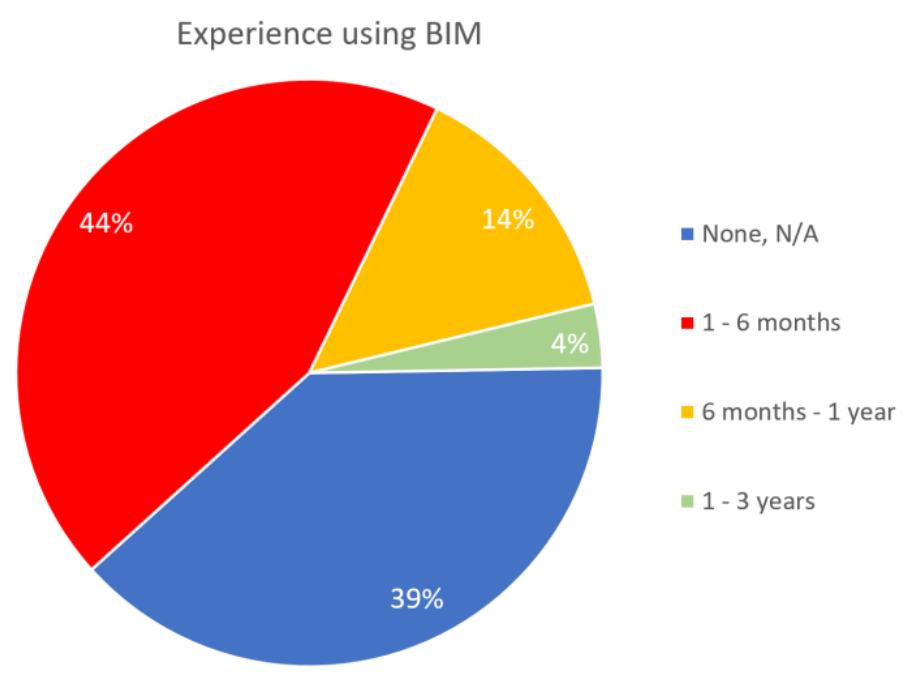

FIG. 4: Participant experience in using BIM

\subsection{Individual- and team-level reflections: project and team performance}

The overall satisfaction was assessed in a 5 point scale. While WSU members reported a satisfactory score of 3.73, NICMAR students showed a satisfactory score of 4.45. An open ended question on 'what they liked or did not like about the project' captured the following responses as presented in Table 2.

Table 2: Individual Reflections about the Project

\begin{tabular}{lll}
\hline University & Liked about the project & Did not like factors \\
\hline \multirow{2}{*}{ WSU } & International exposure & Time zone difference \\
& Global talent and viewpoint & Communication issues \\
& Realistic exercise & Time crunch \\
& Working in different time zones & Technology issues \\
& Communicating with diverse people & Coordination issues, language barrier \\
& Able to see the 'big picture' now & Too short a timeframe to interact and get to \\
& Learning different design perspectives & know each other \\
& Industry trend & Would prefer video interaction \\
\hline \multirow{2}{*}{ Global exposure } & Time zone difference \\
& Learned new software & Communication and coordination issues \\
& Importance of Collaboration & Would prefer interaction other than email \\
Virtual team work & alone \\
New ideas & Short timeline \\
Coordination with diverse culture & No follow-up \\
Realistic project & \\
\hline & Hands on experience & Lack of coordination \\
\hline
\end{tabular}

In summary, the respondents from both the universities appreciated the global exposure they had through this experiment and considered it as an opportunity to learn from diverse perspectives by collaborating in differing time zones and most importantly, observed that getting a hands-on experience on a realistic project was a rewarding 
experience. Participants commented that 'collaboration between majors' was a positive experience and 'working with architects ... along with NICMAR replicated the communication and collaboration that we will see in the job as CMs'. Additionally, participants gained a new perspective on 'how design principles are done globally'. Few respondents also observed that the virtual collaboration was a growing trend and therefore perceived this as a rich experience. However, the respondents also voiced out their dislike on the project with respect to communication gap, wider time-zone difference, technology related issues leading to collaboration challenges, need for richer medium of communication and finally, the limited time frame of the project to get to know the team members.

Observing on the project related challenges, the top five reasons cited by the respondents included: i) understanding scope of the project (42\%), ii) using differing units of measurement - lack of standardized means and methods (31\%), iii) data interpretation issues (32\%) iv) project complexity (16\%), and v) lack of model quality as evident from Fig. 5.

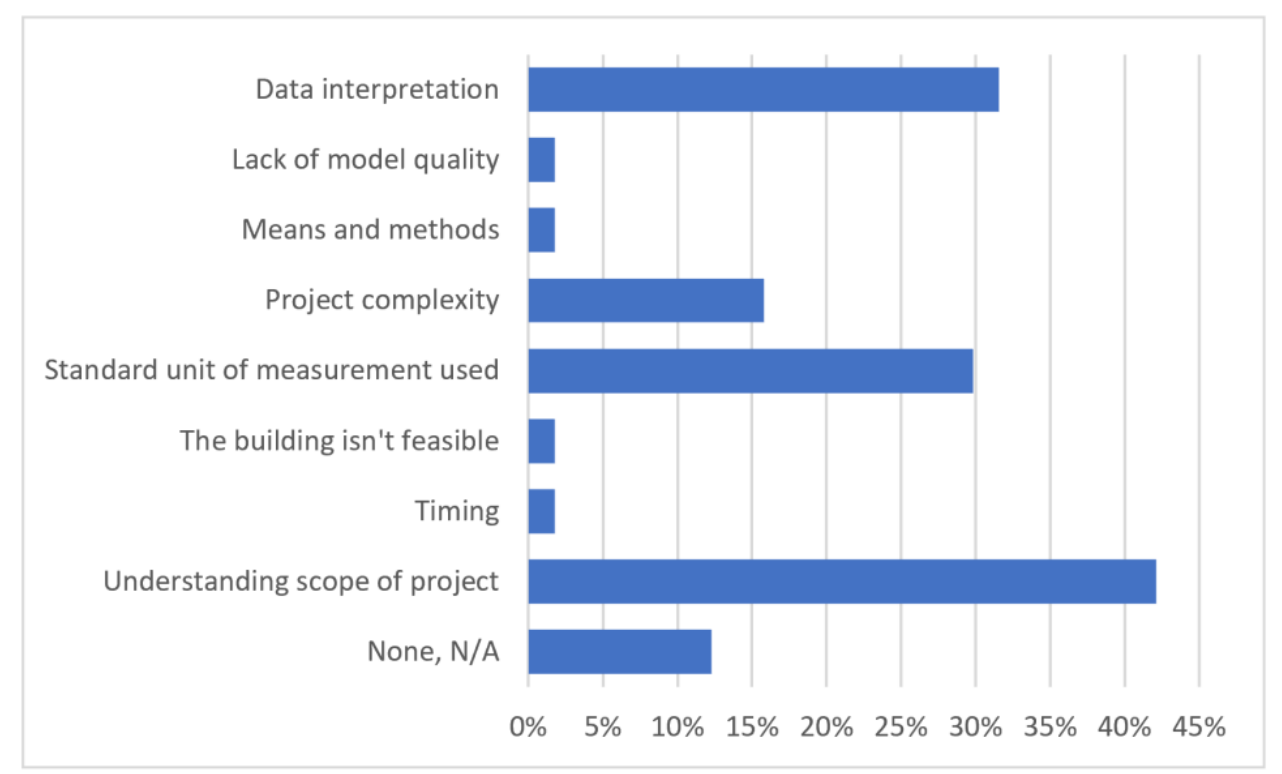

\section{FIG. 5: Project related challenges}

Observing on the team level challenges, the top six reasons cited included: i) discrepancy in level of detail required $(43 \%)$, ii) aligning meeting schedules (40\%), iii) unclear roles and responsibilities (28\%), iv) technical competency $(10 \%)$, v) problem solving ability (9\%) evident in Fig. 6, and vi) inadequate response from global partners $(7 \%)$.

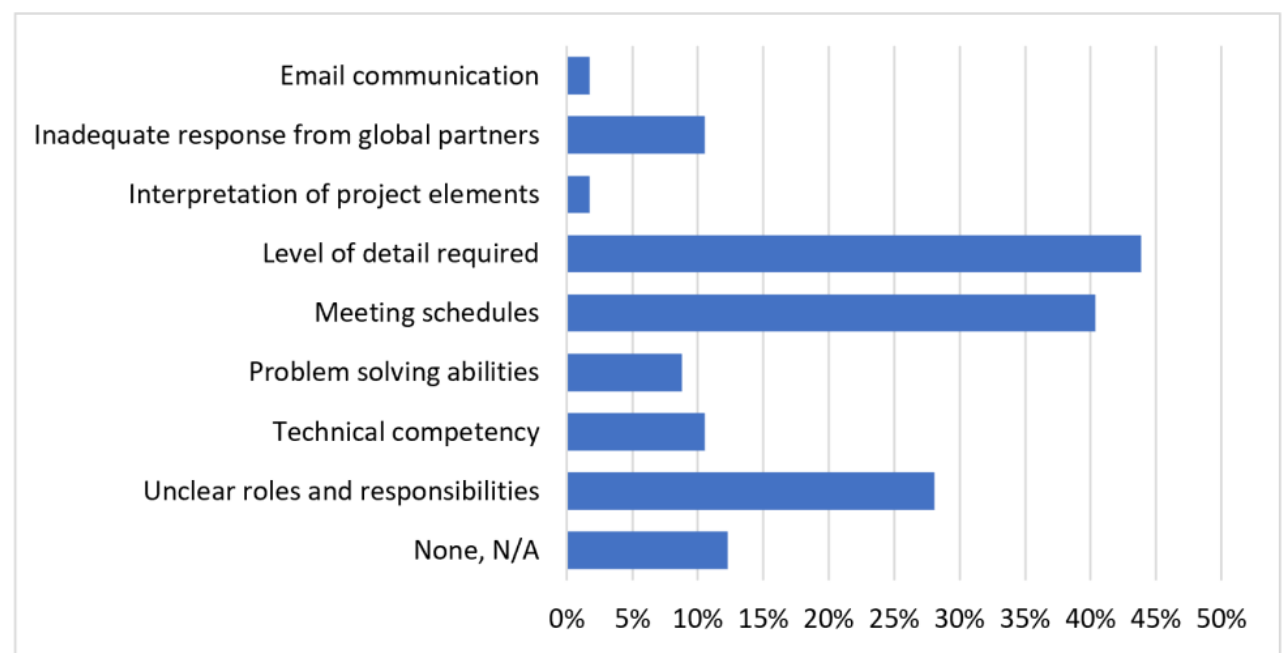

FIG. 6: Team related challenges 
In effect, the participants cited various types of process challenges. For instance, participants noted coordination issues primarily due to time-zone difference ( $88 \%$ of respondents) and virtuality ( $28 \%$ of respondents). Participants encountered cultural challenges due to difference in country specific construction methods (72\%) and linguistic (12\%). Technology related issues included: limited media richness and version control issues in the Revit software. Communication issues were experienced such as delay in response and lack of clarity. Team related issues included lack of cohesion as not all members were participative in e-mails, limited discussions and absence of rich media of communication. Respondents also reported data interpretation issues due to difficulty in understanding some of the 2D drawings, insufficient technical data and specifications leading to ambiguity and misinterpretations.

Further questions in the survey tried to capture the response mechanisms that the teams adopted when faced with a challenge. Some of the members have responded informing about the team strategies that they adopted which included: i) asking more questions, ii) keeping up-to-date with each other's progress, iii) planning in advance, iv) planning to ask the right questions, v) decision to communicate every 48 hours, vi) using richer medium of communication such as Skype, Facebook and WhatsApp, vii) clarifying with faculty or project manager, viii) discussing with team member who had misunderstood, ix) following up the schedule and $\mathrm{x}$ ) constantly letting team members know what is due every week. In sum, it was evident that member's roles and responsibility in the collaborative exercise were perceived to be significant.

Citing the effect of behavioral aspects in performance, the respondents observed that the project and team related conflicts such as team members not taking responsibilities were also due to personality traits like casual approach (33\%) of team members, poor negotiation abilities (14\%) and poor leadership skills (7\%). To cope with these, some of the team members played the role as a facilitator. Alternatively, $33 \%$ of the respondents informed that they did not find the need to have a facilitator to steer performance, and an additional $12 \%$ stated they 'all worked together' with one commenting 'through the BIM execution plan [a facilitator] was not needed'.

\subsection{BIM execution plan and BIM modeling experience}

BIM Execution Plan (BEP) was designed as a pre-process intervention strategy to reduce the team opacity and motivate members to commit and perform the task. It was of interest to understand if the teams had foremost adhered to the BEP (Fig. 7) and subsequently what were the perceived benefits and limitations.

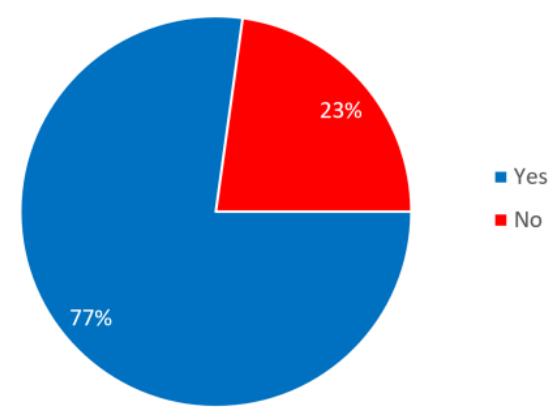

FIG. 7: Adherence to BIM Execution Plan

As evident from Figure 6,77\% of the members observed that their team had adhered to the BEP. The top three benefits voiced by the respondents included: i) it made the task collaborative, ii) we were all on the same page, iii) there was no forced cooperation, but just the need to honor the responsibility. The other observations as cited in the open-ended questions included: i) it had a defined objective, ii) we could foresee the complexity, iii) we did not have to do it alone, iv) allowed us to sync our tasks, v) helped us to manage the time, vi) we all knew what was going on throughout the process, vii) helped visualize the tasks and set-up constant checks. From the responses, it was clear that BIM Execution Plan did act as an enabler for the teams to span geographical, cultural and temporal boundaries and reduce the team opacity caused by virtual interaction.

The respondents also observed the challenges for effective implementation of BEP in the process. For instance, the top four reasons cited, which were insightful, included: i) lack of obligation - 'developing a BIM plan was a good exercise, however no one had an obligation to follow it', ii) delays \& follow-up issues - 'when tasks were delayed, the counterparts found it difficult to adhere to BEP', iii) the plan merely served as a guideline as it was not detailed, and finally, iv) lack of practice and knowledge to effectively integrate or implement it. 
The 3D and 4D modeling tasks provided the teams with an opportunity to enhance their technical software learning skills. The respondents observed that the project location was their primary criteria to build and design. Due to lack of knowledge of the software and the needed learning curve, several teams reported rework on the 3D model. The model allowed them to detect clashes and review constructability issues. Some of the clashes or errors detected included: i) missing walls or multi-surfaced walls rather than a solid flat wall, ii) columns and beam were found projecting beyond the wall or ceiling, iii) all columns were built as a single unit which made it difficult to select a single element, iv) absence of HVAC room and ducts (cultural difference), v) improper sequencing of activities in $4 \mathrm{D}$, and $\mathrm{v}$ ) redundant beams and columns. However, $42 \%$ of the respondents believed that their model was reliable to the end user and were satisfied with the learning outcomes.

\subsection{Lessons learnt and recommendations}

The respondents were asked to state their individual and team level lessons learnt. Interesting insights were evident. For instance, the respondents informed that this exercise: $i$ ) it made me see how collaborative the industry is, ii) it takes a team to complete a model, iii) construction in India is certainly different than in US. As a recommendation, some of the suggestions cited were: i) engage early on, ii) be patient, iii) do not procrastinate and iv) 'you have to annoy people for them to respond sometimes'.

To a question on 'what factors were critical for success', the predominant response was: Team work and BIM execution plan. Some of the other project critical success factors enumerated included: project coordination, continuing communication, time management, team working skills and leadership skills - all of which played an important role. That apart, personality traits such as: i) punctuality, ii) seriousness towards work, iii) dedication, iv) willingness to work, $v$ ) openness to new idea - were equally significant for effective performance.

The recommendations cited for firms executing projects through this business model included: i) communicate expectations early-on, ii) create a BIM plan and stick to it, iii) both the end teams should understand the culture, communication and type of construction done in other countries for successful project completion, iv) be openminded and seek reasoning, v) do a descriptive role planning and documentation, vi) must have clarity in scope and level of detail.

The participants in general showed a positive response for working on similar exercises in future and recommended make it compulsory in the curriculum. When asked 'what they would do differently, if given a chance to work again on the same exercise?' One of the respondents observed:

'Meet in the beginning to plan our deliverables for each of the partners and make sure we have a clear understanding of what we should make this model out to be. Make sure each partner is involved in the model and that we get the expert opinion from our team to create a project at the end that can be built with ease'.

Yet another respondent observed: 'I will find a way to make everyone follow BEP, if I re-do the experiment'. In effect, the success of a project was characterized by a-priori detailed planning and team involvement. It is evident that the participants perceived the importance of BEP for successful BIM modeling process. It can therefore be said that BEP can be an enabler to structure the process for virtually distributed teams. However, its effective integration during modeling process would depend on several parameters including training of the team members and commitment to stick to a detailed BIM plan.

\section{DISCUSSION}

This study foremost aimed to explore the role of project teams in temporary organizing endeavor. The findings showed that the participating students from both the universities appreciated the globally distributed team experiment for the exposure and the opportunity that it provided to work on a realistic project using advanced tools like BIM. The respondents from both the universities termed it as a 'rich experience.' However, the participants highlighted several challenges. Some of which included technology related issues, primarily due to absence of rich communication media, leading to coordination challenges such as delay in response, lack of clarity and misinterpretations. While other issues such as time-zone difference have been reported in similar studies conducted earlier, it was interesting to note the team strategies adopted to overcome these issues. As informed by the respondents, some of the strategies included: 'asking more questions, keeping up-to-date with each other's 
progress, planning in advance, asking the right questions, making a schedule to communicate on alternate days and following up the schedule or constantly letting team members know what is due every week'.

Team strategies exhibited explicate member's efforts to organize and manage the project process proactively rather than adopting a reactive approach or control mechanisms to measure performance. This intuitively leads to an important question pertaining to project performance that has been less explored, for instance, 'how is the performance of global project execution controlled and measured?' or 'should the performance be controlled?'. In this context, it is important to understand that while projects deliver outputs, processes deliver outcomes. Global projects (Orr et al., 2011) and Global virtual teams (Hertel et al., 2005) are temporary endeavours. However, the aim of such an endeavour is to harmonize tasks, optimize performance to achieve success rather than standardize work procedures. Thus, as several researchers connote including Mossolly (2015) and Sackey et al. (2015), the objective here is not to integrate work practices and procedures rather it aims at coordinating tasks for successful outcome which could in due course lead to emergence of informal work practices as identified by Leonardi and Bailey (2008) in their study on collaborative tools in an outsourcing firm. Coordination is therefore a key construct in global project execution and a priori planning aims to reduce the risks in the uncertain and dynamic environment in which the teams execute tasks as also informed by other researchers including Whyte (2013), Liu et al. (2017) and Boton et al. (2018).

Second, taking a socio-technical approach, BEP was introduced to the teams for the collaborative experiment alone as a pre-process intervention strategy. In this regard, the members' voiced a positive opinion observing that 'BEP made the task collaborative and as it had a defined objective, the team members could foresee the complexity, which in turn allowed them to sync their tasks, manage the time and set-up constant checks.' Overall, it was observed that 'developing a BIM plan was a good exercise'. Voicing on its limitations, the members however observed that 'no one had an obligation to follow it, which led to lack of commitment to adhere'. BEP was the foremost exercise that brought all the team members together on a common platform and allowed them to plan the process, discuss to understand the project, clarify and set goals and formulate an execution strategy. In effect, BEP, with its structured methodology allowed the team members to get involved and commit to task instantly, overriding the need for fraternization or trust development in the short-span project (Jarvenpaa and Keating, 2012). The issues due to virtualness and lack of trust was therefore mitigated by deploying intervention strategy that allowed the members to structure the process and clarify their roles and responsibilities. Thus, it can be inferred that BEP can act as a pre-process intervention strategy for distributed teams in collaborative projects. However, sufficient knowledge and practice would be required by team members to commit and effectively implement BEP in BIM projects.

The experiment also exposed the students to a wider perspective of the construction industry like how collaborative the industry was and emphasized the importance of team work. It exposed the students to difference in regulatory systems across national boundaries. Mossolly (2015) argues that all the proposed definitions of global projects are actually missing to mention one of the key characteristic feature - 'the differences in regulatory frameworks'. Researchers including Mahalingam and Levitt (2007) have distinctly demonstrated the institutionalized project setting and the institutional conflicts that arise in cross-cultural collaborations. In this study, respondents remarks such as 'construction in India is far more different than in US' reflect on the teams' realization on the institutional differences that are embedded in construction projects and the need to overcome the knowledge gaps in virtual collaborations.

The team members also agreed that individual personality traits such as punctuality, seriousness towards work, dedication, willingness to work, and openness to new ideas were significant parameters for effective performance. Even though the study was a short span exercise, participants observed the need to negotiate during the process. In this context, Mossolly (2015) argue that a successful BIM process can only be achieved through negotiation of intervention plans that also support end-user's goals. In this study, 'confronting' the issues and 'compromising' were two major negotiation strategies adopted by the teams. However, few counter parts of the team also voiced out using an 'avoidance' strategy. For instance, one of the members informed that even though the received BIM model had errors, they did not voice out the concern to their counterparts and instead re-did the model at their end.

In sum, based on the individual and team reflections, it can be said that organizations have to tap the potential and knowledge of project teams to avoid re-inventing the wheel in the long run. Further, the global teams can be instrumental communities of practice to share and transfer tacit knowledge in organizations (Wenger, 1998). 


\section{CONCLUSION}

This study was a global collaborative experiment between two participating universities, namely, NICMAR Pune, India and WSU, USA. Taking a socio-technical perspective, two aspects were explored: the role of project teams in temporary organizing and the role of BEP as a pre-process intervention strategy. The findings showed that coordinating project tasks virtually was found to be challenging. Organizations adopting a similar business model must therefore consider pre-process or during process intervention strategies to cope. The BIM Execution Plan allowed members to clarify their roles, foresee project complexity, structure and a priori plan the process. Though the plan was not adhered by all members, the participants observed the need to plan and implement BEP more effectively. Several individual and team level observations were found such as proactive approach and sensitivity towards institutional differences across nations.

Taking a socio-technical approach, therefore offered interesting insights. However, due to a short-span study and limited data, the findings cannot be generalized or probed further. It is therefore recommended that for a holistic understanding, more similar studies, with longer project durations, are explored to identify the role of pre-process, during process or post-process interventions to foster successful project outcomes in global virtual collaborations. Kunz and Fischer (2020) point out that larger companies would soon use Virtual Design and Construction more widely within their geographically and technically diverse operations which in turn could perpetuate the growth of global sourcing strategies. This study is therefore a stepping stone in this direction. In the context of academics and curriculum, this exercise was well-received by the students from both the participating universities who termed it as a 'rich experience'. It offered insight to faculty coordinators as well to stipulate clear guidelines, define and allocate team member roles as an intervention strategy for more accountability.

\section{ACKNOWLEDGEMENTS}

We would like to acknowledge the valuable feedback of the students from both the universities who participated in this experiment.

\section{REFERENCES}

Akkirman, A.D. and Harris, D.L. (2005), "Organizational communication satisfaction in the virtual workplace", Journal of Management Development, Vol. 24 No. 5, pp. 397-409.

Anantatmula, V., \& Thomas, M. (2010). Managing Global Projects: A Structured Approach for Better Performance. Project Management Journal, 41, 60-72.

Anderson, R. (1998). Intuitive inquiry: A transpersonal approach. In W. Braud \& R. Anderson, Transpersonal research methods for the social sciences: Honoring human experience (69-94). Thousand Oaks, CA: Sage Publication.

Anumba, C. J., Ugwu, O., Newnham, L., and Thorpe, A. (2002). "Collaborative design of structures using intelligent agents." Automation in Construction, 11(1), 89-103.

Becerik-Gerber, AM ASCE, B., Ku, K., \& Jazizadeh, F. (2012). "BIM-enabled virtual and collaborative construction engineering and management." Journal of Professional Issues in Engineering Education and Practice, 138(3), 234-245.

Bernould, L.E. and T.S. Lee (2010) Experimental Research in Construction, ASCE Journal of Construction Engineering and Management, 136(1), 26-35.

Bos, N., Olson, J. S., Gergle, D., Olson, G. M., \& Wright, Z. (2002). Effects of four computer-mediated communications channels on trust development. Proceedings of CHI 2002. New York, NY: ACM Press.

Boton, C., D. Forgues, and G. Halin, (2018) “A framework for Building Information Modeling implementation in engineering education," Canadian Journal of Civil Engineering.

Cannon-Bowers, J. A., Tannenbaum, S. I., Salas, E., \& Volpe, C. E. (1995). Defining competencies and establishing team training requirements. In R.A. Guzzo \& E. Salas (Eds.), Team effectiveness and decision making in organizations (pp. 333-380). San Francisco, CA: Jossey-Bass. 
Cannon-Bowers, J. A., Salas, E., \& Converse, S. (1993). Shared mental models in expert team decision making. In N. J. Castellan, Jr. (Ed.), Individual and group decision making (pp. 221-246). Hillsdale, NJ: LEA.

Carey, J. M., \& Kacmar, C. J. (1997). The impact of communication mode and task complexity on small group performance and member satisfaction. Computers in Human Behavior, 13, 23-49.

Creswell, John W. (1998). Qualitative inquiry and research design: Choosing among five traditions. Thousand Oaks, CA: Sage.

Criminale, A and S, Langar (2017) Challenges with BIM Implementation: A Review of Literature, 53rd ASC Annual International Conference Proceedings, Copyright by the Associated Schools of Construction

Comu,S., J.Iorio and C. Dossick (2013) Quantifying the impact of facilitation on Transactive Memory System Formation in Global Virtual Project Networks, ASCE Journal of Construction Engineering and Management, 139(3), 294-303.

Computer Integrated Construction Reseaerch Program (2010), Building Information Modeling Execution Planning Guide, Advances in Civil Engineering 11, Computer Integrated Construction Research Group, Pennsylvania State University, State College, PA, USA

Cooley, L. (2020). Fostering human connection in the Covid-19 virtual health care realm. Nejm Catalyst Innovations in Care Delivery.

Daft, R. L. and R.H. Lengel (1986) Organizational information requirements, media richness and structural design. Management Science, 32(5), 554.

DiMarco, M., J. Taylor, and P. Alin (2010) The emergence and role of cultural boundary spanners in global engineering project networks. ASCE Journal of Management in Engineering, 26(3), 123-132.

Dossick, C.S., Homayouni, H. and Lee, G. (2015) Learning in Global Teams: BIM Planning and Coordination, International Journal of Automation and Smart Technology, 5(3), 119-135

Dossick, C., Anderson, A., Azari, R., Iorio, J., Neff, G. and Taylor, J. (2014). "Messy Talk in Virtual Teams: Achieving Knowledge Synthesis through Shared Visualizations," ASCE Journal of Management in Engineering, 10.1061/(ASCE)ME.1943-5479.0000301, A4014003.

Dossick, C.S. and G. Neff (2010) Organizational divisions in BIM-enabled commercial construction. ASCE Journal of Construction Engineering and Management, 136(4), 459-467.

Eastman, C., Teicholz, P., Sacks, R., and Liston, K. (2011). BIM handbook: A guide to building information modeling for owners, managers, designers, engineers and contractors, Wiley, 648.

Elmualim, A., and Gilder, J. (2014). "BIM: Innovation in design management, influence and challenges of implementation.” Architecture, Engineering and Design Management, 10(3-4), 183-199

Espinosa, J.A., J.N. Cummings, J.M. Wilson and B.M. Pearce (2003) Team boundary issues across multiple global firms. Journal of Management Information Systems, 19(4), 157-190.

Fiore, S. M., Salas, E., Cuevas, H. M., \& Bowers, C. A. (2003). Distributed coordination space: Toward a theory of distributed team performance. Theoretical Issues in Ergonomics Science, 4, 340-363.

Gibson, C.B. and J.L. Gibbs (2006) Unpacking the concept of virtuality: The effects of geographic dispersion, electronic dependence, dynamic structure, and national diversity on team innovation. Administrative Science Quarterly, 51, 451-495.

Hertel, G.T., Geister, S. \& Konradt, U. (2005). Managing virtual teams: A review of current empirical research. Human Resource Management Review, 15, 69-95.

Hendrick, H. W. (1997). Organizational design and macroergonomics. In G.Salvendy (Ed.), Handbook of human factors and ergonomics (pp. 594-636). New York, NY: John Wiley \& Sons.

Iorio, J. \& Taylor, J.E. (2015). Precursors to engaged leaders in virtual project teams. International Journal of Project Management, 33(2), pp.395-405. 
Iorio. J, G. Peschiera, J.E. Taylor and L. Korpela (2011) Factors impacting usage patterns of collaborative tools designed to support global virtual design project networks. Journal of Information Technology in Construction, 16, 209-230.

Jansen, H (2010). The Logic of Qualitative Survey Research and its Position in the Field of Social Research Methods. Forum: Qualitative Social Research, 11(2), Art. 11.

Jarvenpaa, S and B. Ives (1994), "The Global Network Organization of the Future: Information Management Opportunities and Challenges," Journal of Management Information Systems, 10, 25-57.

Jarvenpaa, S.L. and E. Keating (2012) Global offshoring of engineering project teams: trust asymmetries across cultural borders, The Engineering Project Organization Journal 2, 71-83.

Kayworth, T. R., \& Leidner, D. E. (2002). Leadership effectiveness in global virtual teams. Journal of management information systems, 18(3), 7-40.

Kunz, J and Fischer, M (2020): Virtual design and construction, Construction Management and Economics, DOI: 10.1080/01446193.2020.1714068.

Kim, S., D. Ph, and S. Chin (2017), "Measurement of construction BIM value based on a case study of a largescale building project," Journal of Management in Engineering, 33(6), 1-10.

Leonardi, P.M. and D.E. Bailey (2008) Transformational technologies and the creation of new work practices: Making implicit knowledge explicit in task based offshoring. MIS Quarterly, 32(2), 411-436.

Levina, N. and E. Vaast (2005) The emergence of boundary spanning competence in practice: Implications for information systems implementation and use. MIS Quarterly, Special Issue on Knowledge management, 29(2), 1-29.

Lin, Yu-Cheng, Yen-Pei Chen, Wan-Ting Huang and Chia-Chun Hong (2016) Development of BIM Execution Plan for BIM Model Management during the Pre-Operation Phase: A Case Study, Buildings 6, 8.

Liu, Y., S. van Nederveen, and M. Hertogh (2017) "Understanding effects of BIM on collaborative design and construction: an empirical study in China," International Journal of Project Management, 35(4), 686-698.

Mahalingam, A. and R.E. Levitt (2007) Institutional theory as a framework for analyzing conflict on global projects. ASCE Journal of Construction Engineering and Management, 133(7), 517-528.

Malhotra, A., Majchrzak, A., \& Rosen, B. (2007). Leading virtual teams. Academy of Management perspectives, 21(1), 60-70.

Malhotra, A., Majchrzak, A., Carman, R., \& Lott, V. (2001). Radical innovation without collocation: A case study at Boeing-Rocketdyne. MIS quarterly, 229-249.

May, A., \& Carter, C. (2001). A case study of virtual team working in the European automotive industry. International Journal of Industrial Ergonomics, 27(3), 171-186.

Maznevski, M. L., \& Chudoba, K. M. (2000). Bridging space over time: Global virtual team dynamics and effectiveness. Organization science, 11(5), 473-492.

Merschbrock, C. and B. E. Munkvold (2015), "Effective digital collaboration in the construction industry-a case study of BIM deployment in a hospital construction project," Computers in Industry, 73, 1-7.

Messner, J., C. Chen and G. Joseph (2007) Effective use of the global engineering workforce. The Construction Industry Institute, Research Report, 211(11), October.

Mossolly, M (2015) Global Projects: A Conceptual Review on Execution Attitude in Multinational Corporations, Procedia, Elseiver, 28th IPMA World Congress, IPMA, Rotterdam, The Netherlands.

Newman, S. A., \& Ford, R. C. (2021). Five Steps to Leading Your Team in the Virtual COVID-19 Workplace. Organizational Dynamics, 50(1), 100802.

Oakley, J. (2012). “Getting a BIM rap: Why implementations fail, and what you can do about it." AECbytes Viewpoint.

Orr, R.J., Scott, W.R., Levitt, R.E., Artto, K. and Kujala, J. (2011). Global Projects: Institutional and Political Challenges (1st ed.). Cambridge: Cambridge University Press. 
Perkmann, M. (2003). Cross-Border Regions in Europe: Significance and Drivers of Regional Cross-Border CoOperation. European Urban and Regional Studies, 10, 153-171.

Poirier, E. A., D. Forgues, and S. Staub-French (2017) "Understanding the impact of BIM on collaboration: a Canadian case study,” Building Research and Information, 45(6), 681-695.

Phelps, A. F. and M. J. Horman (2010) Ethnographic theory-building research in construction. Journal of Construction Engineering and Management, 136(1), 58-65.

PwC FS Viewpoint (2012). Projects without Borders: It's all about Execution. USA: www.pwc.com.fsi

Ramalingam, S. and A. Mahalingam (2011) Enabling conditions for the emergence and effective performance of technical and cultural boundary spanners in global virtual teams. Engineering Project Organization Journal, $1(2), 121-141$.

Sackey, E., M. Tuuli, and A. Dainty (2015) Sociotechnical Systems Approach to BIM Implementation in a Multidisciplinary Construction Context J. Manage. Eng., 2015, 31(1): A4014005

Scott, W.R., R.E. Levitt and R.J. Orr (Eds.) (2011) Global projects: Institutional and political challenges. Cambridge: Cambridge University Press.

Strauss, A., and Corbin, J. (1998). Basics of qualitative research: Techniques and procedures for developing grounded theory, Sage, Thousand Oaks, CA.

Wenger, E. (1998) Communities of Practice: Learning, Meaning, and Identity, Cambridge University Press

Whillans, A., Perlow, L., \& Turek, A. (2021). Experimenting during the shift to virtual team work: Learnings from how teams adapted their activities during the COVID-19 pandemic. Information and Organization, 31(1), 100343.

Whyte, J. (2013). "Beyond the computer: Changing medium from digital to physical." Information and Organization, 23(1), 41-57. 